\title{
Therapeutic strategies involving survivin inhibition in cancer
}

\section{Running title: Survivin inhibition in cancer therapy}

David Martínez-García ${ }^{1,2}$, Noemí Manero-Rupérez ${ }^{1, *}$, Roberto Quesada ${ }^{3}$, Luís KorrodiGregório $^{1 *}$, Vanessa Soto-Cerrato ${ }^{1,2 *}$

${ }^{1}$ Department of Pathology and Experimental Therapeutics, Faculty of Medicine, University of Barcelona, Barcelona, Spain

${ }^{2}$ Institut d'Investigació Biomèdica de Bellvitge (IDIBELL), L'Hospitalet de Llobregat, Barcelona, Spain

${ }^{3}$ Department of Chemistry, Universidad de Burgos, Burgos, Spain

*Corresponding authors:

Dr. Vanessa Soto-Cerrato and Dr. Luís Korrodi-Gregório, University of Barcelona, Pavelló Central, 5a Planta, 5002, C/Feixa Llarga s/n, L'Hospitalet de Llobregat, Barcelona 08907, Spain. E-mail:vvsoto@ub.edu; luiskgregorio@gmail.com.

¥ Present address: Hospital del Mar Medical Research Institute, Barcelona Biomedical Research Park, Barcelona, Spain.

\section{Acknowledgements}

Authors want to thank Dr. Martin Kotev for his technical assistance in figure 1. Partial financial support provided by the Spanish government and the EU (Instituto de Salud Carlos III, FIS PI13/00089) as well as FEDER and the Consejería de Educación Junta de Castilla y León (BU092U16) is gratefully acknowledged. 


\begin{abstract}
Survivin is a small protein that belongs to the inhibitor of apoptosis protein family. It is abundantly expressed in tumors compared to adult differentiated tissues, being associated with poor prognosis in many human neoplasms. This apoptotic inhibitor has a relevant role in both the promotion of cancer cell survival and in the inhibition of cell death. Consequently, aberrant survivin expression stimulates tumor progression and confers resistance to several therapeutic strategies in a variety of tumors. In fact, efficient survivin down-regulation or inhibition results in spontaneous apoptosis or sensitization to chemotherapy and radiotherapy. Therefore, all these features make survivin an attractive therapeutic target to treat cancer. Currently, there are several survivin inhibitors under clinical evaluation, although more specific and efficient survivin inhibitors are being developed. Moreover, novel combination regimens targeting survivin together with other therapeutic approaches are currently being designed and assessed. In this review, recent progress in the therapeutic options targeting survivin for cancer treatment is analyzed. Direct survivin inhibitors and their current development status are explored. Besides this, the major signalling pathways implicated in survivin regulation are described and different therapeutic approaches involving survivin indirect inhibition are evaluated. Finally, promising novel inhibitors under preclinical or clinical evaluation as well as challenges of developing survivin inhibitors as a new therapy for cancer treatment are discussed.
\end{abstract}

Keywords: survivin inhibitors, smac mimetics, apoptosis, anticancer therapy, chemoresistance, IAPs. 


\section{Introduction}

Cancer is a heterogeneous group of diseases that results not just from aberrant cellular proliferation but also from lack of well-regulated cell death. Resistance to apoptosis is one important evasion mechanism by which tumor cells may present chemoresistance and thus contribute to cancer progression. Consequently, molecules involved in regulation of apoptosis are considered potential targets for cancer therapy. In this regard, survivin, the smallest member of the inhibitor of apoptosis protein (IAP) family, has recently emerged as an attractive drug target due to its dual role in cancer, both in cell cycle progression and apoptosis inhibition. In this review, the molecular mechanisms that regulate survivin gene expression and protein function are summarized, as well as specific survivin inhibitors and other therapeutic strategies involving survivin inhibition are discussed.

\subsection{IAPs function and structure}

The IAP family embraces a functionally and structurally related group of proteins that function as endogenous cellular inhibitors of apoptosis in response to daily stresses and insults. Due to its relevance as negative regulators of programed cell death, a dysregulation of IAPs is closely related to cancer development and drug resistance ${ }^{1}$.

Structure of all mammalian IAPs members contains one to three defining baculovirus IAP repeat (BIR) domains encoding a zinc-finger motif typically arranged at the $\mathrm{N}$-terminus of the protein (Figure 1a). Although the BIR domain is shared by all members of the IAP family, not all BIR-containing proteins exhibit antiapoptotic functions ${ }^{2}$. This domain mediates protein recognition and protein-protein interactions ${ }^{3}$. In addition to the BIR domain, several IAP family members contain a zinc-finger domain called RING (really interesting new gene), which functions as an E3 ubiquitin ligase, an ubiquitin-associated (UBA) domain, a ubiquitinconjugating (UBC) domain, and/or a caspase-recruitment domain (CARD).

Among all the IAPs, survivin is the smallest member of the IAP family. Encoded by BIRC5 gene (baculoviral inhibitor of apoptosis repeat-containing 5), mapped to chromosome 17q25, survivin is a $16.5 \mathrm{kDa}$ protein that contains only a single $\mathrm{N}$-terminus BIR domain linked to a Cterminal $\alpha$-helical coiled coil domain. The latter domain is important for the interaction and formation of the chromosomal passenger complex (CPC), proper segregation of chromosomes and cytokinesis during cell division ${ }^{4,5}$. A dimerization domain at two different locations in the linear sequence of survivin allows it to form a stable homodimer that seems to carry out its mitotic activity, while the monomeric form of survivin is mostly associated with its antiapoptotic activity ${ }^{6,7}$ (Figure $1 \mathrm{~b}$ and $1 \mathrm{c}$ ). Moreover, different functions of survivin seem to be affected by differential subcellular localization, being the nuclear survivin related to cell division regulation while cytosolic survivin is believed to function as apoptotic suppressor (Figure 2$)^{8}$. Additionally, a small pool of survivin can be found in the mitochondria, from where is rapidly released to the cytosol in response to cell death stimulation and confers resistance to apoptosis ${ }^{9}$.

Although the overexpression of survivin inhibits both extrinsic and intrinsic apoptosis pathways contributing to cancer progression, the exact molecular mechanism remains unknown. It has been reported a direct binding of survivin to effector caspases, but a prevailing model is that survivin inhibits apoptosis by interacting with other proteins (Figure 2). One of these interactions is a complex formation between survivin and X-linked inhibitor of apoptosis protein (XIAP) ${ }^{10}$. This IAP-IAP complex enhances XIAP stability against ubiquitindependent degradation, increasing in this way the ability of XIAP for inhibiting caspases ${ }^{11}$. 
Another mechanism proposed is the formation of the complex between survivin and hepatitis B X-interacting protein (HBXIP), which binds to procaspase 9 preventing its recruitment to the apoptosome and later activation ${ }^{12}$.

\subsection{Survivin as a promising therapeutic target}

Due to its dual role both in cell cycle promotion and apoptosis inhibition, survivin has been considered an ideal target for anticancer therapy. Indeed, several molecular approaches that block survivin expression and/or function are emerging as promising therapeutic strategies in cancer ${ }^{13}$. Remarkably, survivin is almost undetectable in most normal differentiated tissues, but prominently expressed in most cancer malignancies ${ }^{14}$. This expression pattern provides selectivity over the tumor cells, thus decreasing the potential side effects in treated patients. Moreover, survivin overexpression has already been correlated with tumor prognosis, being considered a biomarker with a negative correlation on patient clinical outcome and drug resistance in many cancers ${ }^{15}$. Altogether, survivin overexpression in tumors and its key biological roles promoting carcinogenesis and chemoresistance, makes survivin a promising therapeutic target.

\section{Pharmacological options targeting survivin}

Since survivin has emerged as an ideal target for cancer drug discovery, many survivin inhibitors have been reported in the literature. Some of them are specific direct inhibitors (Figure 2, table 1) but others do not directly bind and interact with survivin protein itself, instead, they usually target other biomolecules and ultimately reduce survivin expression (Figure 3, table 2). In the following sections, we discuss the available information about survivin inhibitors developed so far, as well as the direct or indirect mechanisms by which they repress survivin.

\subsection{Survivin direct inhibitors: targeting survivin gene or protein}

\subsubsection{Transcriptional inhibition of survivin}

The inhibition of survivin gene expression is a therapeutic strategy under clinical development with the final aim of counteracting the overexpression of survivin in tumor cells. For this purpose, several small-molecules inhibiting the survivin gene promoter or mRNA have been studied.

YM155 was the first identified small-molecule inhibitor that targets and suppresses specifically the activity of the survivin promoter, regardless of p53 status ${ }^{16}$. Interestingly, it suppressed survivin gene promoter and induced apoptosis in prostate cells as well as promoted tumor regression in human prostate PC3 ectopic xenograft tumors ${ }^{16}$. Other preclinical studies showed the promising anti-cancer properties of YM155 against a panel of 119 human cancer cell lines with an average inhibitory concentration $\left({ }^{\prime} C_{50}\right)$ of $15 \mathrm{nM}$. Moreover, continuous 3- or 7-day YM155 infusion (1-10 mg/kg) in xenograft model demonstrated significant antitumor activity without significant toxicity, measured through bodyweight loss ${ }^{17}$. Phase I study reported YM155 as a well-tolerated anticancer drug that showed some efficacy against blood cancers ${ }^{18}$. However, in phase II studies, YM155 showed modest single-agent activity against non-small cell lung carcinoma (NSCLC), but with a disease control rate similar to another second-line agents for advanced NSCLC ${ }^{19}$. The combination of 
YM155 with carboplatin and paclitaxel also exhibited a favorable safety profile but failed to demonstrate an improvement in response rate in advanced NSCLC ${ }^{20}$.

However, despite having evidence supporting that YM155 can antagonize survivin expression, recent data support that YM155 is a DNA damaging agent where suppression of survivin is a secondary event, probably a consequence of transcriptional repression ${ }^{21}$. Similarly, other study also suggests that inhibition of survivin occurs via suppression of EGFR signaling and its downstream factors ${ }^{22}$. Therefore, YM155 may not be only considered a specific survivin inhibitor.

On the other hand, a recent study identified other compound targeting survivin by high throughput screening of chemical libraries following in vitro and in vivo analysis ${ }^{23}$. This compound, named FL118, is a nonselective small-molecule inhibitor of survivin expression that structurally resembles the topoisomerase I inhibitor, irinotecan. Its antitumor activity results from inhibiting survivin promoter activity and survivin gene expression. In addition, FL118 also downregulates the expression of myeloid cell leukemia 1 (Mcl-1) and some IAPs, such as XIAP and cellular inhibitor of apoptosis 2 (c-IAP2) ${ }^{23}$. FL118 effectively inhibited cancer cell growth at concentrations lower of $1 \mathrm{nM}$ in a p53 status-independent manner. The in vivo studies revealed that FL188 has greater antitumor efficacy without significant toxicity compared with leading first-line chemotherapeutics ${ }^{23}$.

In addition to small-molecules targeting survivin gene promoter, antisense oligonucleotides have also been developed to inhibit survivin expression. LY2181308 is one example of singlestrand antisense oligonucleotide that targets survivin by binding to and degrading its mRNA preventing its translation into protein and thus, limiting survivin expression. LY2181308 showed significant reduction of both survivin mRNA and protein, as well as cell-cycle arrest, cell-death induction and tumor growth inhibition in several tumor cell lines and human tumor xenografts ${ }^{24}$. Several clinical studies have been carried out showing a favorable safety profile but mixed clinical outcomes ${ }^{25-27}$. As an example, while LY2181308 showed synergistic benefits in patients with refractory or relapsed acute myeloid leukemia when combined with cytarabine and idarubicin ${ }^{26}$, no benefit was observed against solid tumors when LY2181308 was used as a single agent or in combination with docetaxel/prednisone ${ }^{27}$.

SPC3042 (EZN-3042), another antisense oligonucleotide, was identified as a new agent with higher potency for survivin mRNA inhibition compared to former antisense agents, including LY2181308 ${ }^{28}$. However, SPC3042 not only targets survivin mRNA but also has significant effect over B-cell lymphoma 2 (Bcl-2) mRNA. Downregulation of survivin expression using SPC3042 led to cell cycle arrest, pronounced cellular apoptosis and sensitization of prostate cancer cells to taxol treatment, both in vitro and in vivo. EZN-3042 showed, as a single agent, a $60 \%$ downmodulation of survivin mRNA in tumors of A549 and Calu- 6 lung xenograft models and $37-45 \%$ of tumor growth inhibition. In addition, when EZN-3042 was combined with paclitaxel, $83 \%$ of tumor growth inhibition was achieved ${ }^{29}$. Despite these promising outcomes, phase I trial of EZN-3042 was terminated due its dose-limiting toxicity ${ }^{30}$.

Finally, other gene therapy-based approaches are currently being studied, especially in combination with conventional chemotherapeutics. It has recently been demonstrated that small interfering (si) RNA against survivin, combined with temozolomide or etoposide, induced a synergistic cytotoxic effect in glioblastoma cells ${ }^{31}$. Moreover, the combination of the micro RNA miR-542-3p mimic in combination with paclitaxel significantly inhibited in vivo tumor growth of HER2-overexpressing breast cancer cells, overcoming their chemoresistance ${ }^{32}$. 


\subsubsection{Protein-protein interaction abrogation}

\subsubsection{Smac mimetics}

Second mitochondria-derived activator of caspase (SMAC/DIABLO) is a proapoptotic protein released from mitochondria upon apoptotic stimulation and promotes cytochrome cdependent apoptosis by binding to and antagonizing IAPs. In this sense, SMAC/DIABLO binds to XIAP releasing caspase- 9 from the complex, leading to apoptosis activation. On the other hand, cytosolic survivin is able to bind to SMAC/DIABLO, through its AVPI peptide binding region, inhibiting its pro-apoptotic functions ${ }^{33}$. Furthermore, survivin overexpression can also diminish the pro-apoptotic functions of SMAC/DIABLO by delaying its release from mitochondria through direct union after apoptotic stimuli ${ }^{34}$. Withanone, a natural product derived from roots of Withania somnifera, was studied as a possible competitor of SMAC/DIABLO for its binding site in survivin protein. Computational docking analysis showed that withanone binds to survivin BIR domain in the same hydrophobic cavity as that of SMAC/DIABLO, therefore being able to interfere with its inhibitory activity against caspases ${ }^{35}$. Although the anticancer properties of withanone have already been studied in several cancer cell lines ${ }^{36}$, experimental analysis are needed to confirm whether this compound specifically binds and inhibits survivin. Similarly, analogs of the phenolic component of black pepper piperine have also been described as potential survivin inhibitors by binding to the hydrophobic cavity of the BIR domain ${ }^{37}$. Piperine was capable to inhibit cell growth and induce apoptosis in several types of cancer cells, such as human colon cancer cells ${ }^{38}$, and suppressed tumor growth and metastasis in mice models, but more studies are needed to determine whether its anticancer potential is mediated through survivin inhibition. In a more recent work, using similarity-based virtual screening for the AVPI peptide in the survivin-SMAC crystal complex, UC-112 was identified as a potent and selective survivin inhibitor ${ }^{39}$. UC-112 showed potent cell growth inhibition in human melanoma and prostate cancer cell lines, as well as antitumor activity in in vivo studies. Furthermore, survivin levels were strongly downregulated upon UC-112 treatment in vitro and in vivo. Based on the UC-112 scaffold, new survivin inhibitors, being the most potent ones the $4 \mathrm{~g}$ and $10 \mathrm{f}$, were designed and synthesized ${ }^{40,41}$. Compared to UC-112, its analog $4 \mathrm{~g}$ showed an activity improvement of four folds in growth inhibition of cancer cell lines. Moreover, both compounds maintained the high selectivity for survivin showed by its parent compound UC-112. In vivo studies also showed an effective suppression of tumor growth and strong induction of cancer cell apoptosis in tumor tissues.

All this data, along with the promising outcomes given by other IAP-specific SMAC mimetics ${ }^{42}$, which are under evaluation in early clinical trials both as monotherapy or in rational combination therapies, encourage the study of compounds with this mechanism of action.

\subsubsection{Hsp90-survivin inhibitors}

Another well-studied protein interaction is the association between heat shock protein 90 (Hsp90) and survivin. Hsp90 directly binds, through its $\mathrm{N}$ domain, to the BIR domain of survivin ${ }^{43}$. Besides this, it has been studied how the chaperone function of $\mathrm{Hsp9O}$ is required to preserve survivin stability in vivo and disruption of this complex by using $\mathrm{Hps} 90$ inhibitors triggers loss of survivin via proteasomal-dependent degradation. Blockage of survivin-Hsp90 complex formation promoted apoptosis and mitotic defects in cultured cells. Hence, molecular 
antagonists of survivin-Hsp90 interaction may provide another rational approach to treat cancer.

Shepherdine, a small peptidomimetic, was rationally designed for this purpose ${ }^{44}$. Shepherdine makes extensive contact with the $\mathrm{N}$ domain of $\mathrm{Hsp90}$, thus destabilizing survivin and inducing massive death of tumor cells by apoptotic and nonapoptotic mechanisms. Shepherdine not only affects survivin expression but also destabilized other Hsp90 client proteins, however, it has been proved its good selectivity, because it does not affect normal cells while maintaining excellent antitumor activity. Systemic administration of shepherdine in vivo efficiently inhibited human tumor growth in mice without showing significant toxicity ${ }^{44}$. Based on shepherdine, a non-peptidic small molecule called AICAR (5-aminoimidazole-4carboxamide ribonucleotide) has been identified, through structure- and dynamics-based rational design, as a new Hsp90 inhibitor ${ }^{45}$. AICAR showed the capability of directly binding to the $\mathrm{N}$-terminal domain of $\mathrm{Hsp} 90$ and destabilize its clients proteins, including survivin. Experimental tests showed that AICAR exhibits antiproliferative and proapoptotic activity in melanoma, prostate and cervical cancer cell lines, while not affecting proliferation of normal human fibroblasts ${ }^{45}$.

\subsubsection{Survivin homodimerization inhibitors}

It is known that monomeric and dimeric forms of survivin coexist, being the homodimeric form more related with the promotion of mitosis by enhancing tubulin stability ${ }^{6}$. Thus, development of specific inhibitors targeting the dimerization site of survivin may be a feasible approach to treat cancer. This strategy becomes more attractive due to studies that showed how exposition of the hydrophobic interface of a dimeric protein often cause conformational changes, which leads to destabilization and degradation of the protein ${ }^{46}$. Furthermore, homodimerization interface of survivin is not shared with other IAPs, therefore inhibitors of this site may increase their selectivity against survivin.

Abbott 8 was identified using NMR and affinity-based screening as a small soluble compound that binds to the dimer interface of survivin ${ }^{47}$. Several analogues were further developed reaching compounds with nanomolar affinities, however, more studies are needed to evaluate their anticancer activity.

In this context, using in silico screening targeting the critical dimerization core residues of survivin, LQZ-7 was identified ${ }^{48}$. LQZ-7 was able to dissociate the dimeric survivin into monomers in vitro and to promote its proteasome-dependent degradation in cells. Further analysis of LQZ-7 analogs led to the identification of LQZ-7F, a compound able to disrupt more effectively survivin dimerization, cause proteasome-dependent degradation, mitotic arrest and inhibit cancer cell survival through induction of spontaneous apoptosis. LQZ-7F was also effective in suppressing PC3 xenograft tumor growth and reducing survivin levels, without showing significant toxicity in mice after multiple dosing ${ }^{48}$.

\subsubsection{Mitosis-related proteins inhibitors}

Survivin plays an essential role in cell mitosis, including chromosome segregation and cytokinesis, mostly as an integral component of CPC ${ }^{49}$. It is well documented how depletion of survivin causes cell proliferation arrest, sustained prometaphase blockade, chromosomal defects and cytokinesis failure ${ }^{50}$. Additionally, a distinct pool of subcellular survivin is 
associated with polymerized microtubules, sustaining their stability, thereby contributing to the bipolar spindle assembly ${ }^{50}$.

In this context and using in silico analysis, several hotspot residues related to protein-protein interaction were found in survivin, including its CPC complex interface ${ }^{51}$. Therefore, a pharmacophore model was derived and used to virtually screen databases of compounds. Using this methodology, indinavir, a protease inhibitor approved for the treatment of human immunodeficiency virus (HIV), was identified as an inhibitor of the interaction of survivin with its binding partners, such as CPC complex. Indinavir was able to impart anti-proliferative and apoptotic activity in breast cancer cells, decreasing Aurora B and XIAP proteins and inducing caspase-3 activation. Although preliminary biochemical results indicate that indinavir could inhibit both survivin-Aurora $B$ in the $C P C$, and survivin-XIAP interactions, further investigations are needed to understand the antiproliferative mechanism of action of this compound. In another in silico study, S12, a small molecule that targets a specific cavity adjacent to the survivin dimerization surfaces, was identified ${ }^{52}$. S12 showed disruption of the spindle formation, which led to mitotic arrest of cancer cells, followed by cell death with no apparent toxic effect over non-proliferating and normal resting cells. Moreover, in vivo studies showed how S12 was able to inhibit tumor growth without producing systemic toxicity in animals ${ }^{52}$. Finally, the importance of the protein complex formation between survivin and the small GTPase Ran (Ras-related nuclear protein) has also been studied. Ran is implicated in microtubule stability and mitotic spindle assembly in tumor cells ${ }^{53}$. The small-molecule LLP-3, derived from Abbott 8 compound, showed an effective disruption of the survivin-Ran complex, leading to survival and growth inhibition of glioma stem cells, both in vitro and in vivo ${ }^{54}$.

\subsection{Survivin indirect inhibitors: targeting key cellular signaling pathways}

It has already been shown that survivin expression, either through down or up-regulation, could be triggered by several signaling pathways. The most actively described are shown in Figure 3 and will be discussed below.

\subsubsection{Cell growth, proliferation and survival}

\subsubsection{PI3K/AKT}

The phosphatidylinositol-4,5-bisphosphate 3-kinase (PI3K)/protein kinase B (PKB or AKT) signaling pathway is involved in several cellular functions including cell proliferation, growth and survival. The tyrosine receptor activation, via external signals, leads to class I PI3K recruitment to the plasma membrane and consequent activation to unleash a cascade of phosphorylations that will result in AKT activation. The AKT pathway has abundant downstream components controlling several cellular processes and is inappropriately activated in many cancers. Constitutive activation of PI3K receptor and somatic mutations in any component of the pathway or its negative regulators were observed in many cancers ${ }^{55}$. During normal angiogenesis, the activation of PI3K/AKT pathway through upstream stimulation of vascular endothelial growth factor (VEGF)/vascular endothelial growth factor receptor (VEGFR) or angiopoietin 1 (Ang1)/angiopoietin receptor (Tie2), leads to an increase in survivin expression. Besides this, insulin growth factor (IGF-1)/PI3K/Akt/mammalian target of rapamycin (mTOR) signaling elevates survivin levels in prostate cancer cells via rapid changes in mRNA translation ${ }^{56}$. Likewise, several receptors (e.g. Granulocyte-macrophage colonystimulating factor receptor(GM-CSFR), epidermal growth factor receptor (EGFR) and human 
epidermal growth factor receptor 2 and 3 (HER-2 and HER-3) upregulate survivin levels through this route in cancer ${ }^{32,57}$.

Particularly, PI3K/AKT signaling is a potent regulator of survivin expression through different mechanisms: 1) activation of mTOR/Ribosomal protein $\mathrm{S} 6$ kinase beta-1 (p70S6K) axis induces the translation of various oncogenic proteins such as hypoxia-inducible factor 1-alpha (HIF-1 $\alpha$ ), which in turn control cell survival related genes such as survivin (upregulation) ${ }^{58}$; 2) Mouse double minute 2 homolog (MDM2) negatively regulates the tumor suppressor p53, which decreases survivin expression via direct binding to the promoter ${ }^{59}$; 3) AKT negatively regulates the transcription factors forkhead box protein $\mathrm{O1}$ (FOXO1) and O3a (FOXO3a) that physically associate with the survivin promoter, repressing its expression ${ }^{60}$ and 4) Nuclear factor kappa $B$ (NF-KB), which is regulated upstream by the AKT/inhibitor of NF-KB kinase (IKK) axis, is associated with the transcriptional upregulation of survivin ${ }^{61,62}$.

Accordingly, inhibiting this pathway has become an important strategy in cancer treatment. In breast cancer, herceptin and lapatinib (HER-2 inhibitors) and AG1478 (EGFR inhibitor) inhibit survivin expression ${ }^{63-65}$. In ovarian cancer, similar results were observed with the EGFR inhibitors gefitinib and PD153035 ${ }^{66,67}$. However, most reports have studied the inhibition of PI3K through LY294002 and wortmannin in several types of cancer: breast, colon, liver, ovary, lung and in leukemia ${ }^{60,65,67-72}$. Concerning the inhibition of AKT, MK-2206 strongly blocks survivin in glioma and colon cancer ${ }^{73}$. Moreover, SH5 inhibitor significantly reduces survivin levels in lung cancer ${ }^{68}$ and similar results were observed with AKT inhibitor $\mathrm{X}$ in prostate cancer ${ }^{69}$. Likewise, mTOR inhibitors, more specifically rapamycin, firmly downregulate survivin in glioblastoma, multiple myeloma and prostate cancer ${ }^{58,74}$. The induction of survivin was also inhibited by the NF-KB inhibitors, SN50 and BAY 11-7082 in endothelial cells ${ }^{61,75}$. Additionally, downregulation of survivin was observed with panepoxydone in breast cancer, and this seems to be related with NF-KB inhibition ${ }^{76}$. Cyclooxygenase-2 (COX-2) induces survivin expression through AKT activation in several cancers (e.g. glioblastoma, lymphoma, myeloma, breast, colon and prostate) and this action could be reversed through its inhibitors, celecoxib and etodolac ${ }^{77}$.

\subsubsection{JAK/STAT}

The Janus kinase (JAK)/signal transducer and activator of transcription (STAT) signaling pathway plays a critical role in cell proliferation, differentiation, migration, apoptosis and immunity ${ }^{78}$. A wide range of cytokines, hormones and growth factors, and their respective receptors stimulate the JAK/STAT pathway ${ }^{78}$. JAK activation results in the recruitment and activation of STAT proteins that will then translocate to the nucleus and induce the transcription of target genes, such as survivin ${ }^{78}$. It is known that dysregulation of JAK/STAT pathway participates in cancer development and metastasis ${ }^{78}$.

Interleukin 6 (IL-6), induce STAT3 activation leading to an increase on survivin expression in breast cancer cells ${ }^{79}$. In leukemia, the up-regulation of survivin involving the JAK/STAT signaling pathway is dependent on GM-CSF ${ }^{80}$ and breakpoint cluster region protein (BCR)Abelson murine leukemia viral oncogene homolog $(A B L){ }^{81}$.

Interestingly, after blocking JAK2 kinase with the TG101209 inhibitor, a decrease of survivin is observed in leukemia ${ }^{81}$. Another JAK2 inhibitor known as AG490 ${ }^{82}$ has shown to downregulate survivin in lymphoma as well as leukemia. Similar results were reported with the JAK2 inhibitor SD-1029 for breast and ovary cancers ${ }^{83}$. Our group has also shown that novel indol-based 
tambjamine analogues were able to reduce survivin levels by inhibiting JAK/STAT pathway through an unknown mechanism of action 84 and unpublished data.

\subsubsection{MAPK/ERK}

Mitogen-activated protein kinase (MAPK)/extracellular signal-regulated kinase (ERK) signaling mediates cellular proliferation, differentiation, survival, development, migration and apoptosis. Ligand binding to the tyrosine kinase receptor causes the dimerization and phosphorylation of its cytoplasmic domains. Adaptor proteins bind to the receptor, triggering Rat sarcoma (RAS) GTPase, which in turn activates a cascade of kinases: MAPKKK (Raf, rapid accelerated fibrosarcoma), MAPKK (MEK, mitogen-activated protein kinase kinase)) and MAPK (ERK). Activated ERK is transported to the nucleus where phosphorylates several transcription factors regulating several target genes including survivin. MAPK/ERK signaling is involved in cancer progression, particularly in proliferation and immune escape and numerous mutations have been identified in tumors, such as in RAS genes ${ }^{55}$.

Epidermal growth factor (EGF) induces the activation of MAPK/ERK signaling and increases survivin levels ${ }^{85}$. Cytokines such as Granulocyte-macrophage colony-stimulating (GM-CSF) and the BCR-ABL tyrosine kinase could induce survivin expression via MAPK/ERK dependent mechanism in leukemia ${ }^{86}$. Moreover, HER-2 up-regulation of survivin is regulated by MAPK/ERK signaling, apart from the PI3K/AKT contribution in breast cancer ${ }^{70}$. Similar results were observed with c-Harvey rat sarcoma viral oncogene homolog (c-H-RAS), where both MAPK/ERK and PI3K/AKT are participating in survivin overexpression ${ }^{72}$.

Interestingly, MEK inhibitors significantly reduce survivin levels. In particular, PD98059 in breast cancer ${ }^{65}$ and leukemia, and similar results were described with Cl1040 in leukemia ${ }^{86}$. Besides this, PD0325901 (a Cl1040 derivative) prevented the placental lactogen induction of survivin ${ }^{66}$. The U0126 inhibitor strongly blocks MAPK induction of survivin in leukemia ${ }^{86}$, breast cancer ${ }^{70}$ and keratinocytes ${ }^{72}$. In addition, BCR-ABL inhibition by imatinib significantly hampers MAPK/ERK survivin expression in leukemia cells ${ }^{86}$.

\subsubsection{Cell cycle regulation}

Survivin is expressed in a cell cycle-dependent way and localizes in the mitotic apparatus. The cyclin-dependent kinases (CDKs) 2/4 are active in both $\mathrm{G} 1$ and $\mathrm{S}$ phases and phosphorylate retinoblastoma $(\mathrm{Rb})$ relieving it from the E2F transcription factors to allow the cell cycle transition. Survivin is positively regulated by E2F1, E2F2 and E2F3 through cell cycle-dependent element $(C D E) / c e l l$ cycle genes homology region (CHR) dependent mechanism while is negatively regulated by E2F4 and E2F5 repressors ${ }^{87}$. Moreover, the CDK1/cyclin-B1 pair phosphorylates survivin on Thr34, contributing to its stability and its association with caspases 88.

Some CDKs inhibitors, in addition to arresting the cell cycle, have an interesting ability to induce apoptosis. In addition, CDK inhibitors abrogate survivin phosphorylation on Thr34 leading to its degradation ${ }^{89}$. The specific CDKs inhibitor (purvalanol A) downregulates survivin through JAK/STAT inhibition in gastric cancer [79]. A broad spectrum CDK inhibitor known as flavopiridol inhibits survivin phosphorylation on Thr34, reducing its protein levels in cervical cancer and has shown its antitumor activity in several phase II clinical trials ${ }^{90,91}$. The specific CDK2 inhibitor NU6140 also diminishes survivin expression in cervical and ovary cancers ${ }^{88}$. Finally, Cephalochromin is a selective bacterial inhibitor that reduces the levels of CDK2/cyclin- 
$E$ and $C D K 4 /$ cyclin-D1 pairs producing cell cycle arrest $\left(\mathrm{G}_{0} / \mathrm{G}_{1}\right.$ phase) and consequently decreasing survivin expression and inducing apoptosis ${ }^{92}$.

\subsubsection{Cellular stress: p38MAPK}

The p38MAPK signaling is involved in inflammation, cell cycle, cell death, development, differentiation and senescence ${ }^{93}$. Environmental stresses (e.g. UV and heat) and inflammatory cytokines trigger this pathway by phosphorylation of MAPKKKs. These kinases signal the cascade through MKK3 and MKK6 and finally p38MAPK which will finally activate transcription factors (e.g. p53) that will regulate several target gene expression ${ }^{93}$.

Activation of the p38MAPK route by the COX-2 inhibitor celecoxib induces survivin downregulation in colon cancer cells ${ }^{94}$. Likewise, oxaliplatin, a chemotherapeutic drug, leads to colon cancer cell death through survivin downregulation via p38MAPK pathway and via proteasomal degradation ${ }^{95}$.

\subsubsection{Development and Differentiation}

\subsubsection{TGF $\beta$}

Transforming growth factor beta (TGF- $\beta$ ) signaling controls several cellular functions including cell growth, proliferation, differentiation, development and migration. Upon ligand binding, constitutively active TGF- $\beta$ receptor II (T $\beta R$ RI) recruits and activates by phosphorylation the $T \beta R I$. Due to this activity, Smad proteins, Smad2 and Smad3, are phosphorylated and form a complex with co-Smad (Smad4) in the cytoplasm, which is then translocated to the nucleus where it regulates gene expression, including survivin ${ }^{96}$. Although TGF $\beta$ is an important tumor suppressor, cancer cells subvert this pathway by taking control of the tumor promoting arm ${ }^{96}$. Interestingly, an overexpression of TGF- $\beta 1$ was described in various types of cancer. In addition, inactivating mutations on SMAD2 and SMAD4 were reported in hepatocellular, colorectal and lung cancer ${ }^{96}$.

The activation of the TGF- $\beta$ pathway in colon cancer causes the hypophosphorylation of Rb via Smad3-dependent mechanism, which causes the association of Rb/E2F4 repressive complex to $\mathrm{CDE} / \mathrm{CHR}$ elements of survivin gene promoting its downregulation ${ }^{71,97}$. Similarly, TGF- $\beta$ inhibition of PI3K/AKT signaling through protein kinase $A$ (PKA)/A-kinase anchoring protein (AKAP149)/protein phosphatase 2 (PP2A) may also reduce the survivin levels ${ }^{71,97}$. Furthermore, TGF $\beta$ activation of PKA, leads also to the phosphorylation of survivin in Ser20 inducing its degradation ${ }^{97}$.

\subsubsection{Wnt/ $\beta$-Catenin}

Wnt signaling regulates stem cell pluripotency, differentiation and embryonic development. In absence of Wnt signaling, Adenomatous polyposis coli (APC)/Axin/glycogen synthase kinase 3 beta (GSK-3 $\beta$ ) inhibitory complex leads to the ubiquitination and degradation of $\beta$-catenin. Wnt receptors activation hampers this complex, displacing Axin and inhibiting GSK-3 $\beta$ activity. This leads to $\beta$-catenin accumulation in cytoplasm and its translocation to the nucleus where it binds to Lymphoid enhancer-binding factor (LEF)/TCF transcription factors and co-activators (e.g. CREB-binding protein, CBP) regulating a variety of genes, including survivin ${ }^{98}$.

A variety of Wnt and APC mutations and alterations are frequently observed in cancer ${ }^{98}$. It has been reported that TCF/ $\beta$-catenin induces survivin expression in lung, colorectal and breast cancers ${ }^{63,98,99}$. 
Drugs binding to HER-2 receptor, such as Herceptin (trastuzumab) in breast cancer, compromise $\beta$-catenin stabilization and consequently decrease survivin expression ${ }^{63}$. Furthermore, an antibody against Wnt2 protein, Wnt-2 Ab, induces apoptosis inhibiting this process in lung cancer ${ }^{98}$. Downregulation of $\beta$-catenin and survivin expression by ICG-001 (a $\beta$ catenin/CBP disruptor) was observed in colon cancer ${ }^{100}$.

\subsubsection{Notch}

Notch signaling is involved in important cellular processes such as proliferation, development, differentiation and homeostasis ${ }^{101}$. It mediates cell-cell communication through interaction with transmembrane ligands on adjacent cells. Ligand binding results in Notch receptor cleavage through $\gamma$-secretase releasing the notch intracellular domain (NICD) that is then translocated to the nucleus where it modifies DNA transcription. Particularly, NICD associates with CBF1/Su(H)/Lag1 (CSL) transcription factor in order to activate Notch target genes, including survivin ${ }^{101,102}$. Hypoxia and Jagged-1 ligand activate Notch signaling increasing survivin expression in lung cancer ${ }^{103}$. In addition, HIF-1 $\alpha$ promotes Notch induction of survivin, suggesting that HIF1- $\alpha$ interacts with NICD facilitating the CSL transcription factor association with a RBP-JK site in the survivin promoter ${ }^{102}$.

Aberrant Notch signaling has been associated with tumorigenesis and cancer progression in lung, pancreas and breast cancer models. In fact, mutations on Notch receptors and consequently nuclear overexpression of NICD were described in leukemia and lymphoma ${ }^{101}$.

Under hypoxia, both Echinomycin (HIF-1 $\alpha$ inhibitor) and inhibitors of $\psi$-secretase (MRK-003 and a specific peptide inhibitor), decrease survivin expression in lung and breast cancers ${ }^{102}$.

\subsubsection{Others}

Survivin promoter has several sites for the transcription factor $\mathrm{Sp} 1$ and mutations on some of those sites reduce survivin expression by $60-80 \%$ in cervical cancer ${ }^{104,105}$. In contrast, Sp1 could also recruit transcriptional repressors such as p53, DNMT1 and HDAC and consequently suppress survivin promoter activity ${ }^{106}$. Interestingly, Sp1 inhibition by mithramycin A or oxaliplatin significantly decreased survivin promoter activity in colon and esophageal cancers 106,107. Moreover, the small molecule terameprocol significantly decreased survivin levels by hampering Sp1 binding to survivin promoter and through the downregulation of CDK1 that leads to survivin degradation. This effect was observed in colorectal, prostate, hepatic, erythroleukemia and breast cancers ${ }^{108}$.

Survivin has yet binding sites to other transcription factors as we have mentioned previously. Several of these transcription factors are important survivin inductors, like the GATA-1 ${ }^{109}$, cmyc ${ }^{110}$ and DEC1 ${ }^{111}$ transcription factors. KLF5 binds directly to survivin promoter on three specific sites inducing its expression, but could also interact with p53 and block its repression on survivin promoter ${ }^{112}$. In addition, it has been reported that survivin is targeted by GLI2 transcription factor, a Hedgehog signaling effector. Defective activation of hedgehog signaling has been described in many cancers. $11 \mathrm{GLI}$ binding sites were found in survivin promoter. Inhibiting Hedgehog signaling through SMO inhibitor cyclopamine strongly reduces survivin promoter activity in melanoma ${ }^{105}$. Besides, an specific inhibitor of GLI known as GANT61 also significantly inhibits survivin promoter activity and consequently reduces survivin protein in melanoma, colon, lung, pancreatic and adrenal gland cancers ${ }^{105}$. Furthermore, palmatine has recently been described to inhibit GLI/collagen type 1 alpha 1 (COL1A1) in stellate cells and survivin in cancer cells ${ }^{113}$. 
Other molecules have also shown to reduce survivin levels in several cancers: an inhibitor of CRM1 (KPT-185), a protein that plays a critical role in the nuclear export of proteins; SF002-961 (natural lactone) through indirect inhibition of transcription factors, STAT3 and NF-KB ${ }^{114}$ and several small molecules (e.g. GDP366, the HIV protease inhibitor Nelfinavir and the derivative of retinoic acid tretinoin) through an unknown mechanism of action ${ }^{115-117 .}$

\section{Concluding Remarks and future perspectives}

Many preclinical studies have extensively demonstrated that survivin has a relevant role in promoting tumor growth as well as inducing resistance to chemotherapy in several neoplasms. Moreover, survivin shows a differential expression, being preferentially and abundantly expressed in tumors but not in adult differentiated tissues. Altogether, these features make survivin a promising therapeutic target to treat cancer. However, early clinical data indicates that the first direct inhibitors of survivin available show modest activity as single agents and, in some cases, dose-limiting toxicities. These are the cases of LY2181308 oligonucleotide or the small-molecule inhibitor YM155. This limited response may be due to deficiencies in complete and selective survivin inhibition in patients and to tumor heterogeneity. Therefore, inhibitors with more specific mechanisms targeting survivin, such as smac mimetics or survivin homodimerization inhibitors, are expected to show better clinical results. On the other hand, several indirect survivin inhibitors are currently in clinical trials, such as flavopiridol or lapatinib, although their effects may be due to the combination of survivin inhibition together with other mechanisms of action ${ }^{64,91}$. Additionally, efforts directed at identification of specific biomarkers useful for the selection of patients benefiting from the treatment should be made.

Immunotherapy is another therapeutic approach under current evaluation. It is focused on targeting survivin through the stimulation of the immune system to provoke a direct response against the tumor. Some clinical trials, like vaccination with survivin-2B80-88 peptide ${ }^{118}$, have shown limited clinical responses. On the other hand, the good tolerability demonstrated offer promise to optimize this therapeutic approach. Indeed, there is some expectation in several phase I and II clinical trials using survivin vaccines (NCT03029403, NCT03349450, among others), which are currently recruiting patients to evaluate its safety, tolerability and effectiveness in combination with other treatments.

Finally, it is anticipated that the maximum therapeutic effect of survivin inhibitors will be completely achieved in combination regimens. Since targeting survivin sensitizes cancer cells to apoptosis ${ }^{119}$, it is expected that survivin inhibitors will enhance the apoptotic effect induced by traditional chemotherapeutic drugs or radiotherapy, showing synergistic effects and overcoming the treatment resistance observed in some patients. Several studies combining chemotherapeutics with chemical survivin inhibitors have already demonstrated this ability 86,91 and some others are currently under evaluation. This is also the case for novel gene therapy-based approaches targeting survivin, when administered in combination with chemotherapeutics. Preliminary studies have demonstrated that these combinations are able to enhance cancer cells sensitivity to chemotherapeutics ${ }^{31}$ and overcome chemoresistance in certain types of cancers ${ }^{32}$.

The reviewed results underscore survivin as an attractive and promising cancer drug target. Future efforts may be focused on the development of synergistic combinations between direct or indirect survivin inhibitors, or gene therapy-based approaches, together with chemotherapeutic drugs in order to efficiently treat cancer. 


\section{References}

1. Rathore R, McCallum JE, Varghese E, Florea AM, Busselberg D. Overcoming chemotherapy drug resistance by targeting inhibitors of apoptosis proteins (IAPs). Apoptosis : an international journal on programmed cell death. 2017;22(7):898-919.

2. Schimmer AD. Inhibitor of apoptosis proteins: translating basic knowledge into clinical practice. Cancer research. 2004;64(20):7183-7190.

3. Srinivasula SM, Ashwell JD. IAPs: what's in a name? Molecular cell. 2008;30(2):123135.

4. Li F, Ackermann EJ, Bennett CF, et al. Pleiotropic cell-division defects and apoptosis induced by interference with survivin function. Nature cell biology. 1999;1(8):461-466.

5. Chantalat L, Skoufias DA, Kleman JP, Jung B, Dideberg O, Margolis RL. Crystal structure of human survivin reveals a bow tie-shaped dimer with two unusual alpha-helical extensions. Molecular cell. 2000;6(1):183-189.

6. Pavlyukov MS, Antipova NV, Balashova MV, Vinogradova TV, Kopantzev EP, Shakhparonov MI. Survivin monomer plays an essential role in apoptosis regulation. The Journal of biological chemistry. 2011;286(26):23296-23307.

7. Verdecia MA, Huang H, Dutil E, Kaiser DA, Hunter T, Noel JP. Structure of the human anti-apoptotic protein survivin reveals a dimeric arrangement. Nature structural biology. 2000;7(7):602-608.

8. Li F, Yang J, Ramnath N, Javle MM, Tan D. Nuclear or cytoplasmic expression of survivin: what is the significance? International journal of cancer. 2005;114(4):509-512.

9. Dohi T, Beltrami E, Wall NR, Plescia J, Altieri DC. Mitochondrial survivin inhibits apoptosis and promotes tumorigenesis. The Journal of clinical investigation. 2004;114(8):1117-1127.

10. Eckelman BP, Salvesen GS, Scott FL. Human inhibitor of apoptosis proteins: why XIAP is the black sheep of the family. EMBO reports. 2006;7(10):988-994.

11. Dohi T, Okada K, Xia F, et al. An IAP-IAP complex inhibits apoptosis. The Journal of biological chemistry. 2004;279(33):34087-34090.

12. Marusawa $\mathrm{H}$, Matsuzawa $\mathrm{S}$, Welsh $\mathrm{K}$, et al. HBXIP functions as a cofactor of survivin in apoptosis suppression. The EMBO journal. 2003;22(11):2729-2740.

13. Garg H, Suri P, Gupta JC, Talwar GP, Dubey S. Survivin: a unique target for tumor therapy. Cancer cell international. 2016;16:49.

14. Kanwar JR, Kamalapuram SK, Kanwar RK. Survivin signaling in clinical oncology: a multifaceted dragon. Medicinal research reviews. 2013;33(4):765-789.

15. Rodel F, Sprenger T, Kaina B, et al. Survivin as a prognostic/predictive marker and molecular target in cancer therapy. Curr Med Chem. 2012;19(22):3679-3688.

16. Nakahara T, Kita A, Yamanaka K, et al. YM155, a novel small-molecule survivin suppressant, induces regression of established human hormone-refractory prostate tumor xenografts. Cancer research. 2007;67(17):8014-8021.

17. Nakahara T, Kita A, Yamanaka K, et al. Broad spectrum and potent antitumor activities of YM155, a novel small-molecule survivin suppressant, in a wide variety of human cancer cell lines and xenograft models. Cancer science. 2011;102(3):614-621.

18. Tolcher AW, Mita A, Lewis LD, et al. Phase I and pharmacokinetic study of YM155, a small-molecule inhibitor of survivin. Journal of clinical oncology : official journal of the American Society of Clinical Oncology. 2008;26(32):5198-5203.

19. Giaccone G, Zatloukal P, Roubec J, et al. Multicenter phase II trial of YM155, a smallmolecule suppressor of survivin, in patients with advanced, refractory, non-small-cell lung cancer. Journal of clinical oncology : official journal of the American Society of Clinical Oncology. 2009;27(27):4481-4486. 
20. Kelly RJ, Thomas A, Rajan A, et al. A phase I/II study of sepantronium bromide (YM155, survivin suppressor) with paclitaxel and carboplatin in patients with advanced nonsmall-cell lung cancer. Annals of oncology : official journal of the European Society for Medical Oncology. 2013;24(10):2601-2606.

21. Glaros TG, Stockwin LH, Mullendore ME, Smith B, Morrison BL, Newton DL. The "survivin suppressants" NSC 80467 and YM155 induce a DNA damage response. Cancer chemotherapy and pharmacology. 2012;70(1):207-212.

22. Na YS, Yang SJ, Kim SM, et al. YM155 induces EGFR suppression in pancreatic cancer cells. PloS one. 2012;7(6):e38625.

23. Ling X, Cao S, Cheng $Q$, Keefe JT, Rustum YM, Li F. A novel small molecule FL118 that selectively inhibits survivin, Mcl-1, XIAP and cIAP2 in a p53-independent manner, shows superior antitumor activity. PloS one. 2012;7(9):e45571.

24. Carrasco RA, Stamm NB, Marcusson E, Sandusky G, Iversen P, Patel BK. Antisense inhibition of survivin expression as a cancer therapeutic. Molecular cancer therapeutics. 2011;10(2):221-232.

25. Talbot DC, Ranson M, Davies J, et al. Tumor survivin is downregulated by the antisense oligonucleotide LY2181308: a proof-of-concept, first-in-human dose study. Clinical cancer research : an official journal of the American Association for Cancer Research. 2010;16(24):6150-6158.

26. Erba HP, Sayar H, Juckett M, et al. Safety and pharmacokinetics of the antisense oligonucleotide (ASO) LY2181308 as a single-agent or in combination with idarubicin and cytarabine in patients with refractory or relapsed acute myeloid leukemia (AML). Investigational new drugs. 2013;31(4):1023-1034.

27. Wiechno P, Somer BG, Mellado B, et al. A randomised phase 2 study combining LY2181308 sodium (survivin antisense oligonucleotide) with first-line docetaxel/prednisone in patients with castration-resistant prostate cancer. European urology. 2014;65(3):516-520.

28. Hansen JB, Fisker N, Westergaard M, et al. SPC3042: a proapoptotic survivin inhibitor. Molecular cancer therapeutics. 2008;7(9):2736-2745.

29. Sapra P, Wang M, Bandaru R, Zhao H, Greenberger LM, Horak ID. Down-modulation of survivin expression and inhibition of tumor growth in vivo by EZN-3042, a locked nucleic acid antisense oligonucleotide. Nucleosides, nucleotides \& nucleic acids. 2010;29(2):97-112.

30. Raetz EA, Morrison D, Romanos-Sirakis E, et al. A phase I study of EZN-3042, a novel survivin messenger ribonucleic acid (mRNA) antagonist, administered in combination with chemotherapy in children with relapsed acute lymphoblastic leukemia (ALL): a report from the therapeutic advances in childhood leukemia and lymphoma (TACL) consortium. Journal of pediatric hematology/oncology. 2014;36(6):458-463.

31. Cruz RQ, Morais CM, Cardoso AM, et al. Enhancing glioblastoma cell sensitivity to chemotherapeutics: A strategy involving survivin gene silencing mediated by gemini surfactant-based complexes. European journal of pharmaceutics and biopharmaceutics : official journal of Arbeitsgemeinschaft fur Pharmazeutische Verfahrenstechnik eV. 2016;104:7-18.

32. Lyu H, Wang S, Huang J, Wang B, He Z, Liu B. Survivin-targeting miR-542-3p overcomes HER3 signaling-induced chemoresistance and enhances the antitumor activity of paclitaxel against HER2-overexpressing breast cancer. Cancer letters. 2018;420:97-108.

33. Song $Z$, Yao X, Wu M. Direct interaction between survivin and Smac/DIABLO is essential for the anti-apoptotic activity of survivin during taxol-induced apoptosis. The Journal of biological chemistry. 2003;278(25):23130-23140.

34. Ceballos-Cancino G, Espinosa M, Maldonado V, Melendez-Zajgla J. Regulation of mitochondrial Smac/DIABLO-selective release by survivin. Oncogene.

2007;26(54):7569-7575. 
35. Wadegaonkar VP, Wadegaonkar PA. Withanone as an inhibitor of survivin: a potential drug candidate for cancer therapy. Journal of biotechnology. 2013;168(2):229-233.

36. Widodo N, Priyandoko D, Shah N, Wadhwa R, Kaul SC. Selective killing of cancer cells by Ashwagandha leaf extract and its component Withanone involves ROS signaling. PloS one. 2010;5(10):e13536.

37. Sattarinezhad E, Bordbar AK, Fani N. Virtual screening of Piperine analogs as Survivin inhibitors and their molecular interaction analysis by using consensus docking, MD simulation, MMPB/GBSA and alanine scanning techniques. Journal of biomolecular structure \& dynamics. 2017;35(8):1824-1832.

38. Yaffe PB, Power Coombs MR, Doucette CD, Walsh M, Hoskin DW. Piperine, an alkaloid from black pepper, inhibits growth of human colon cancer cells via G1 arrest and apoptosis triggered by endoplasmic reticulum stress. Molecular carcinogenesis. 2015;54(10):1070-1085.

39. Wang J, Li W. Discovery of novel second mitochondria-derived activator of caspase mimetics as selective inhibitor of apoptosis protein inhibitors. The Journal of pharmacology and experimental therapeutics. 2014;349(2):319-329.

40. Xiao M, Wang J, Lin Z, et al. Design, Synthesis and Structure-Activity Relationship Studies of Novel Survivin Inhibitors with Potent Anti-Proliferative Properties. PloS one. 2015;10(6):e0129807.

41. Wang Q, Arnst KE, Xue Y, et al. Synthesis and biological evaluation of indole-based UC112 analogs as potent and selective survivin inhibitors. European journal of medicinal chemistry. 2018;149:211-224.

42. Fulda S. Promises and Challenges of Smac Mimetics as Cancer Therapeutics. Clinical cancer research : an official journal of the American Association for Cancer Research. 2015;21(22):5030-5036.

43. Fortugno P, Beltrami E, Plescia J, et al. Regulation of survivin function by Hsp90. Proceedings of the National Academy of Sciences of the United States of America. 2003;100(24):13791-13796.

44. Plescia J, Salz W, Xia F, et al. Rational design of shepherdin, a novel anticancer agent. Cancer cell. 2005;7(5):457-468.

45. Meli M, Pennati M, Curto M, et al. Small-molecule targeting of heat shock protein 90 chaperone function: rational identification of a new anticancer lead. Journal of medicinal chemistry. 2006;49(26):7721-7730.

46. Kubota H. Quality control against misfolded proteins in the cytosol: a network for cell survival. Journal of biochemistry. 2009;146(5):609-616.

47. Wendt MD, Sun C, Kunzer A, et al. Discovery of a novel small molecule binding site of human survivin. Bioorganic \& medicinal chemistry letters. 2007;17(11):3122-3129.

48. Qi J, Dong Z, Liu J, et al. Effective Targeting of the Survivin Dimerization Interface with Small-Molecule Inhibitors. Cancer research. 2016;76(2):453-462.

49. Lens SM, Vader G, Medema RH. The case for Survivin as mitotic regulator. Current opinion in cell biology. 2006;18(6):616-622.

50. Altieri DC. The case for survivin as a regulator of microtubule dynamics and cell-death decisions. Current opinion in cell biology. 2006;18(6):609-615.

51. Sarvagalla S, Cheung CHA, Tsai J-Y, Hsieh HP, Coumar MS. Disruption of protein-protein interactions: hot spot detection, structure-based virtual screening and in vitro testing for the anti-cancer drug target - survivin. RSC Advances. 2016;6(38):31947-31959.

52. Berezov A, Cai Z, Freudenberg JA, et al. Disabling the mitotic spindle and tumor growth by targeting a cavity-induced allosteric site of survivin. Oncogene. 2012;31(15):19381948.

53. Xia F, Canovas PM, Guadagno TM, Altieri DC. A survivin-ran complex regulates spindle formation in tumor cells. Molecular and cellular biology. 2008;28(17):5299-5311. 
54. Guvenc H, Pavlyukov MS, Joshi K, et al. Impairment of glioma stem cell survival and growth by a novel inhibitor for Survivin-Ran protein complex. Clinical cancer research : an official journal of the American Association for Cancer Research. 2013;19(3):631642.

55. Burotto M, Chiou VL, Lee JM, Kohn EC. The MAPK pathway across different malignancies: a new perspective. Cancer. 2014;120(22):3446-3456.

56. Vaira V, Lee CW, Goel HL, Bosari S, Languino LR, Altieri DC. Regulation of survivin expression by IGF-1/mTOR signaling. Oncogene. 2007;26(19):2678-2684.

57. Zhao P, Meng $Q$, Liu LZ, You YP, Liu N, Jiang BH. Regulation of survivin by $\mathrm{PI} 3 \mathrm{~K} / \mathrm{Akt} / \mathrm{p} 70 \mathrm{S6K} 1$ pathway. Biochemical and biophysical research communications. 2010;395(2):219-224.

58. Anandharaj A, Cinghu S, Park WY. Rapamycin-mediated mTOR inhibition attenuates survivin and sensitizes glioblastoma cells to radiation therapy. Acta Biochim Biophys Sin (Shanghai). 2011;43(4):292-300.

59. Mirza A, McGuirk M, Hockenberry TN, et al. Human survivin is negatively regulated by wild-type p53 and participates in p53-dependent apoptotic pathway. Oncogene. 2002;21(17):2613-2622.

60. Guha M, Plescia J, Leav I, Li J, Languino LR, Altieri DC. Endogenous tumor suppression mediated by PTEN involves survivin gene silencing. Cancer research. 2009;69(12):49544958.

61. Li W, Wang $\mathrm{H}$, Kuang $\mathrm{CY}$, et al. An essential role for the Id1/PI3K/Akt/NFkB/survivin signalling pathway in promoting the proliferation of endothelial progenitor cells in vitro. Molecular and cellular biochemistry. 2012;363(1-2):135-145.

62. Khan Z, Khan AA, Yadav H, Prasad G, Bisen PS. Survivin, a molecular target for therapeutic interventions in squamous cell carcinoma. Cellular \& molecular biology letters. 2017;22:8.

63. Zhu $\mathrm{H}$, Zhang $\mathrm{G}$, Wang $\mathrm{Y}$, et al. Inhibition of ErbB2 by Herceptin reduces survivin expression via the ErbB2-beta-catenin/TCF4-survivin pathway in ErbB2-overexpressed breast cancer cells. Cancer science. 2010;101(5):1156-1162.

64. Xia W, Bisi J, Strum J, et al. Regulation of survivin by ErbB2 signaling: therapeutic implications for ErbB2-overexpressing breast cancers. Cancer research. 2006;66(3):1640-1647.

65. Peng XH, Karna P, Cao Z, Jiang BH, Zhou M, Yang L. Cross-talk between epidermal growth factor receptor and hypoxia-inducible factor-1alpha signal pathways increases resistance to apoptosis by up-regulating survivin gene expression. The Journal of biological chemistry. 2006;281(36):25903-25914.

66. Hakonen E, Ustinov J, Palgi J, Miettinen PJ, Otonkoski T. EGFR signaling promotes betacell proliferation and survivin expression during pregnancy. PloS one.

2014;9(4):e93651.

67. Zhou C, Qiu L, Sun Y, et al. Inhibition of EGFR/PI3K/AKT cell survival pathway promotes TSA's effect on cell death and migration in human ovarian cancer cells. International journal of oncology. 2006;29(1):269-278.

68. Belyanskaya LL, Hopkins-Donaldson S, Kurtz S, et al. Cisplatin activates Akt in small cell lung cancer cells and attenuates apoptosis by survivin upregulation. International journal of cancer. 2005;117(5):755-763.

69. Roca H, Varsos Z, Pienta KJ. CCL2 protects prostate cancer PC3 cells from autophagic death via phosphatidylinositol 3-kinase/AKT-dependent survivin up-regulation. The Journal of biological chemistry. 2008;283(36):25057-25073.

70. Siddiqa A, Long LM, Li L, Marciniak RA, Kazhdan I. Expression of HER-2 in MCF-7 breast cancer cells modulates anti-apoptotic proteins Survivin and Bcl-2 via the extracellular signal-related kinase (ERK) and phosphoinositide-3 kinase (PI3K) signalling pathways. BMC cancer. 2008;8:129. 
71. Wang J, Yang L, Yang J, et al. Transforming growth factor beta induces apoptosis through repressing the phosphoinositide 3-kinase/AKT/survivin pathway in colon cancer cells. Cancer research. 2008;68(9):3152-3160.

72. Sommer KW, Schamberger CJ, Schmidt GE, Sasgary S, Cerni C. Inhibitor of apoptosis protein (IAP) survivin is upregulated by oncogenic c-H-Ras. Oncogene. 2003;22(27):4266-4280.

73. Agarwal E, Chaudhuri A, Leiphrakpam PD, Haferbier KL, Brattain MG, Chowdhury S. Akt inhibitor MK-2206 promotes anti-tumor activity and cell death by modulation of AIF and Ezrin in colorectal cancer. BMC cancer. 2014;14:145.

74. Stromberg T, Dimberg A, Hammarberg A, et al. Rapamycin sensitizes multiple myeloma cells to apoptosis induced by dexamethasone. Blood. 2004;103(8):3138-3147.

75. Zhu L, Fukuda S, Cordis G, Das DK, Maulik N. Anti-apoptotic protein survivin plays a significant role in tubular morphogenesis of human coronary arteriolar endothelial cells by hypoxic preconditioning. FEBS Lett. 2001;508(3):369-374.

76. Arora R, Yates C, Gary BD, et al. Panepoxydone targets NF-kB and FOXM1 to inhibit proliferation, induce apoptosis and reverse epithelial to mesenchymal transition in breast cancer. PloS one. 2014;9(6):e98370.

77. Lin J, Hsiao PW, Chiu TH, Chao JI. Combination of cyclooxygenase-2 inhibitors and oxaliplatin increases the growth inhibition and death in human colon cancer cells. Biochem Pharmacol. 2005;70(5):658-667.

78. Rawlings JS, Rosler KM, Harrison DA. The JAK/STAT signaling pathway. Journal of cell science. 2004;117(Pt 8):1281-1283.

79. Gritsko T, Williams A, Turkson J, et al. Persistent activation of stat3 signaling induces survivin gene expression and confers resistance to apoptosis in human breast cancer cells. Clinical cancer research : an official journal of the American Association for Cancer Research. 2006;12(1):11-19.

80. Gu L, Chiang KY, Zhu N, Findley HW, Zhou M. Contribution of STAT3 to the activation of survivin by GM-CSF in CD34+ cell lines. Exp Hematol. 2007;35(6):957-966.

81. Stella $\mathrm{S}$, Tirro $\mathrm{E}$, Conte $\mathrm{E}$, et al. Suppression of survivin induced by a BCRABL/JAK2/STAT3 pathway sensitizes imatinib-resistant CML cells to different cytotoxic drugs. Molecular cancer therapeutics. 2013;12(6):1085-1098.

82. Aoki Y, Feldman GM, Tosato G. Inhibition of STAT3 signaling induces apoptosis and decreases survivin expression in primary effusion lymphoma. Blood. 2003;101(4):15351542.

83. Duan Z, Bradner JE, Greenberg E, et al. SD-1029 inhibits signal transducer and activator of transcription 3 nuclear translocation. Clinical cancer research : an official journal of the American Association for Cancer Research. 2006;12(22):6844-6852.

84. Manuel-Manresa P, Korrodi-Gregorio L, Hernando E, et al. Novel Indole-based Tambjamine-Analogues Induce Apoptotic Lung Cancer Cell Death through p38 Mitogen-Activated Protein Kinase Activation. Molecular cancer therapeutics. 2017;16(7):1224-1235.

85. Wang H, Gambosova K, Cooper ZA, et al. EGF regulates survivin stability through the Raf-1/ERK pathway in insulin-secreting pancreatic beta-cells. BMC Mol Biol. 2010;11:66.

86. Carter BZ, Mak DH, Schober WD, et al. Regulation of survivin expression through BcrAbl/MAPK cascade: targeting survivin overcomes imatinib resistance and increases imatinib sensitivity in imatinib-responsive CML cells. Blood. 2006;107(4):1555-1563.

87. Jiang $\mathrm{Y}$, Saavedra HI, Holloway MP, Leone G, Altura RA. Aberrant regulation of survivin by the RB/E2F family of proteins. The Journal of biological chemistry. 2004;279(39):40511-40520. 
88. O'Connor DS, Grossman D, Plescia J, et al. Regulation of apoptosis at cell division by p34cdc2 phosphorylation of survivin. Proceedings of the National Academy of Sciences of the United States of America. 2000;97(24):13103-13107.

89. Mobahat M, Narendran A, Riabowol K. Survivin as a preferential target for cancer therapy. International journal of molecular sciences. 2014;15(2):2494-2516.

90. Wall NR, O'Connor DS, Plescia J, Pommier Y, Altieri DC. Suppression of survivin phosphorylation on Thr34 by flavopiridol enhances tumor cell apoptosis. Cancer research. 2003;63(1):230-235.

91. Bible KC, Peethambaram PP, Oberg AL, et al. A phase 2 trial of flavopiridol (Alvocidib) and cisplatin in platin-resistant ovarian and primary peritoneal carcinoma: MC0261. Gynecologic oncology. 2012;127(1):55-62.

92. Hsiao CJ, Hsiao G, Chen WL, et al. Cephalochromin induces G0/G1 cell cycle arrest and apoptosis in A549 human non-small-cell lung cancer cells by inflicting mitochondrial disruption. Journal of natural products. 2014;77(4):758-765.

93. Cuadrado A, Nebreda AR. Mechanisms and functions of p38 MAPK signalling. Biochem J. 2010;429(3):403-417.

94. Hsiao PW, Chang CC, Liu HF, Tsai CM, Chiu TH, Chao Jl. Activation of p38 mitogenactivated protein kinase by celecoxib oppositely regulates survivin and gamma-H2AX in human colorectal cancer cells. Toxicol Appl Pharmacol. 2007;222(1):97-104.

95. Liu HF, Hu HC, Chao JI. Oxaliplatin down-regulates survivin by p38 MAP kinase and proteasome in human colon cancer cells. Chem Biol Interact. 2010;188(3):535-545.

96. Colak S, Ten Dijke P. Targeting TGF-beta Signaling in Cancer. Trends in cancer. 2017;3(1):56-71.

97. Chowdhury S, Howell GM, Rajput A, et al. Identification of a novel TGFbeta/PKA signaling transduceome in mediating control of cell survival and metastasis in colon cancer. PloS one. 2011;6(5):e19335.

98. You L, He B, Xu Z, et al. Inhibition of Wnt-2-mediated signaling induces programmed cell death in non-small-cell lung cancer cells. Oncogene. 2004;23(36):6170-6174.

99. Kim PJ, Plescia J, Clevers H, Fearon ER, Altieri DC. Survivin and molecular pathogenesis of colorectal cancer. Lancet. 2003;362(9379):205-209.

100. Emami KH, Nguyen $\mathrm{C}, \mathrm{Ma} \mathrm{H}$, et al. A small molecule inhibitor of beta-catenin/CREBbinding protein transcription [corrected]. Proceedings of the National Academy of Sciences of the United States of America. 2004;101(34):12682-12687.

101. Li L, Tang P, Li S, et al. Notch signaling pathway networks in cancer metastasis: a new target for cancer therapy. Medical oncology. 2017;34(10):180.

102. Palazzo E, Morandi P, Lotti R, et al. Notch Cooperates with Survivin to Maintain Stemness and to Stimulate Proliferation in Human Keratinocytes during Ageing. International journal of molecular sciences. 2015;16(11):26291-26302.

103. Chen $\mathrm{Y}$, Li D, Liu H, et al. Notch-1 signaling facilitates survivin expression in human nonsmall cell lung cancer cells. Cancer Biol Ther. 2011;11(1):14-21.

104. Li F, Altieri DC. Transcriptional analysis of human survivin gene expression. Biochem J. 1999;344 Pt 2:305-311.

105. Vlckova K, Ondrusova L, Vachtenheim J, et al. Survivin, a novel target of the Hedgehog/GLI signaling pathway in human tumor cells. Cell death \& disease. 2016; 7:e2048.

106. Esteve PO, Chin HG, Pradhan S. Molecular mechanisms of transactivation and doxorubicin-mediated repression of survivin gene in cancer cells. The Journal of biological chemistry. 2007;282(4):2615-2625.

107. Ngan CY, Yamamoto $\mathrm{H}$, Takagi A, et al. Oxaliplatin induces mitotic catastrophe and apoptosis in esophageal cancer cells. Cancer science. 2008;99(1):129-139. 
108. Huang RC, Chang CC, Mold D. Survivin-dependent and -independent pathways and the induction of cancer cell death by tetra-O-methyl nordihydroguaiaretic acid. Seminars in oncology. 2006;33(4):479-485.

109. Boidot R, Vegran F, Jacob D, et al. The transcription factor GATA-1 is overexpressed in breast carcinomas and contributes to survivin upregulation via a promoter polymorphism. Oncogene. 2010;29(17):2577-2584.

110. Cosgrave N, Hill AD, Young LS. Growth factor-dependent regulation of survivin by cmyc in human breast cancer. Journal of molecular endocrinology. 2006;37(3):377-390.

111. Li Y, Xie M, Yang J, et al. The expression of antiapoptotic protein survivin is transcriptionally upregulated by DEC1 primarily through multiple sp1 binding sites in the proximal promoter. Oncogene. 2006;25(23):3296-3306.

112. Zhu N, Gu L, Findley HW, et al. KLF5 Interacts with p53 in regulating survivin expression in acute lymphoblastic leukemia. The Journal of biological chemistry. 2006;281(21):14711-14718.

113. Chakravarthy D, Munoz AR, Su A, et al. Palmatine suppresses glutamine-mediated interaction between pancreatic cancer and stellate cells through simultaneous inhibition of survivin and COL1A1. Cancer letters. 2018;419:103-115.

114. Felix S, Sandjo LP, Opatz T, Erkel G. SF002-96-1, a new drimane sesquiterpene lactone from an Aspergillus species, inhibits survivin expression. Beilstein journal of organic chemistry. 2013;9:2866-2876.

115. Shi X, Wang D, Ding K, et al. GDP366, a novel small molecule dual inhibitor of survivin and Op18, induces cell growth inhibition, cellular senescence and mitotic catastrophe in human cancer cells. Cancer biology \& therapy. 2010;9(8):640-650.

116. Gupta V, Samuleson CG, Su S, Chen TC. Nelfinavir potentiation of imatinib cytotoxicity in meningioma cells via survivin inhibition. Neurosurgical focus. 2007;23(4):E9.

117. Carter BZ, Milella M, Altieri DC, Andreeff M. Cytokine-regulated expression of survivin in myeloid leukemia. Blood. 2001;97(9):2784-2790.

118. Tsuruma $\mathrm{T}$, Iwayama $\mathrm{Y}$, Ohmura $\mathrm{T}$, et al. Clinical and immunological evaluation of antiapoptosis protein, survivin-derived peptide vaccine in phase I clinical study for patients with advanced or recurrent breast cancer. Journal of translational medicine. 2008;6:24.

119. Yu X, Zhang Y, Cavazos D, et al. miR-195 targets cyclin D3 and survivin to modulate the tumorigenesis of non-small cell lung cancer. Cell death \& disease. 2018;9(2):193.

120. lizuka D, Ogura A, Kuwabara M, Inanami O. Purvalanol A induces apoptosis and downregulation of antiapoptotic proteins through abrogation of phosphorylation of JAK2/STAT3 and RNA polymerase II. Anti-cancer drugs. 2008;19(6):565-572.

\section{Author biosketches}

Vanessa Soto-Cerrato obtained her bachelor's degree in Biology in 2001, her master's degree in Biomedical Sciences in 2002 and a Ph.D. in Cellular Biology and Pathology in 2007, at the University of Barcelona. During those periods, she worked in Molecular Genetics (Molecular Biology Institute, University of Copenhagen, Denmark) and in Cancer Experimental Therapeutics (School of Medicine, University of Barcelona). Then she joined Ferrer International Pharmaceuticals as a postdoctoral fellow and was involved in Drug Discovery Programs for Oncology, Neurology and Regenerative Medicine. She is currently an Associate Professor at the School of Medicine at the University of Barcelona, where she has been 
involved in different projects regarding the identification and preclinical development of novel proapoptotic anticancer drugs for different types of cancers.

Luís Korrodi-Gregório obtained his B.Sc. degree in Biology from the University of Aveiro, Portugal in 2007 and his Ph.D. degree in Biochemistry from the University of Aveiro in 2012 under the supervision of Prof. Edgar da Cruz e Silva and Prof. Margarida Fardilha. In 2013 he joined as a postdoctoral researcher the Cancer Cell Biology Group under Prof. Ricardo PérezTomás's supervision at the University of Barcelona, Spain, and his research was focused in drug screening and discovering the most promising mechanism of action to tackle cellular internal $\mathrm{pH}$ and apoptosis.

Roberto Quesada obtained his Ph.D. degree in Chemistry at the University of Oviedo in 2002. After postdoctoral appointments at the Trinity College Dublin and the University of Southampton, he moved to the University of Burgos in 2008 as "Ramon y Cajal" Fellow and became Associate Professor in 2012. His research interests include synthetic and supramolecular chemistry, with a focus in biological applications.

David Martínez-García obtained his bachelor's degree in Biomedical Science and his master's degree in Basic and Translational Research in Cancer at the University of Barcelona in 2014 and 2015, respectively. He is currently pursuing a Ph.D. degree in Medicine and Translational Research under the supervision of Dra. Vanessa Soto-Cerrato and Dr. Ricardo Pérez-Tomás. He is working on the study of survivin in tumor progression and chemoresistance in human lung cancer and he is focused on the design and preclinical development of new inhibitors that effectively block survivin, and therefore the progression of this neoplasm, with minimal side effects.

Noemí Manero Rupérez obtained her bachelor's degree in Biomedicine in 2016 and her Master's degree in Basic and Translational Research in Cancer in 2017 at the University of Barcelona, Spain. In the Cancer Cell Biology Research Group, her research was focused on studying the mechanism of action of several novel anticancer and proapoptotic compounds. She is currently pursuing a Ph.D. degree at the Hospital del Mar Medical Research Institute mainly focused on novel drug targets to treat cancer.

\section{Tables}

Table 1. Direct survivin inhibitors.

\begin{tabular}{|l|l|l|l|l|}
\hline Mechanism of & Name & Structure & Clinical & Reference \\
\hline
\end{tabular}




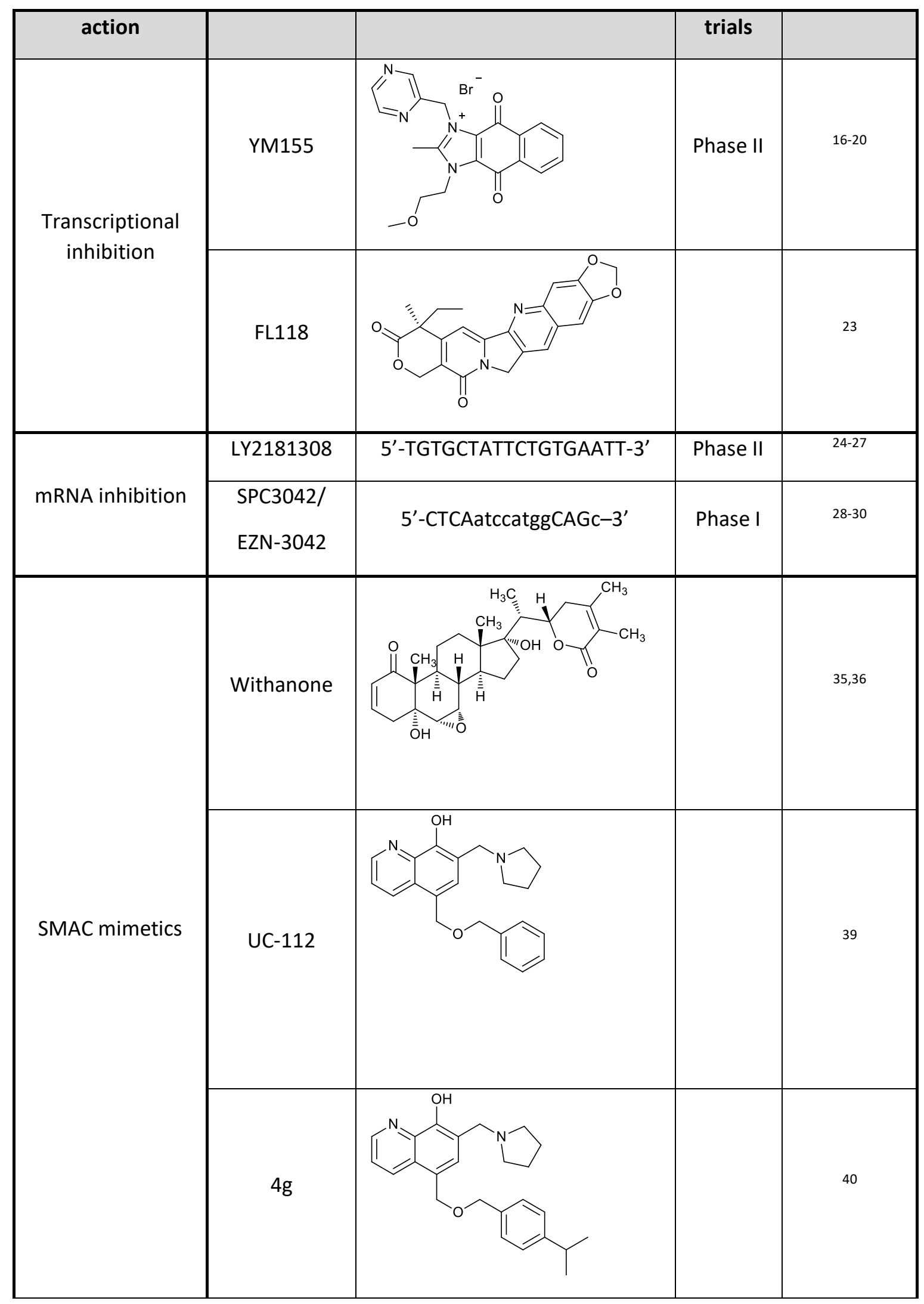




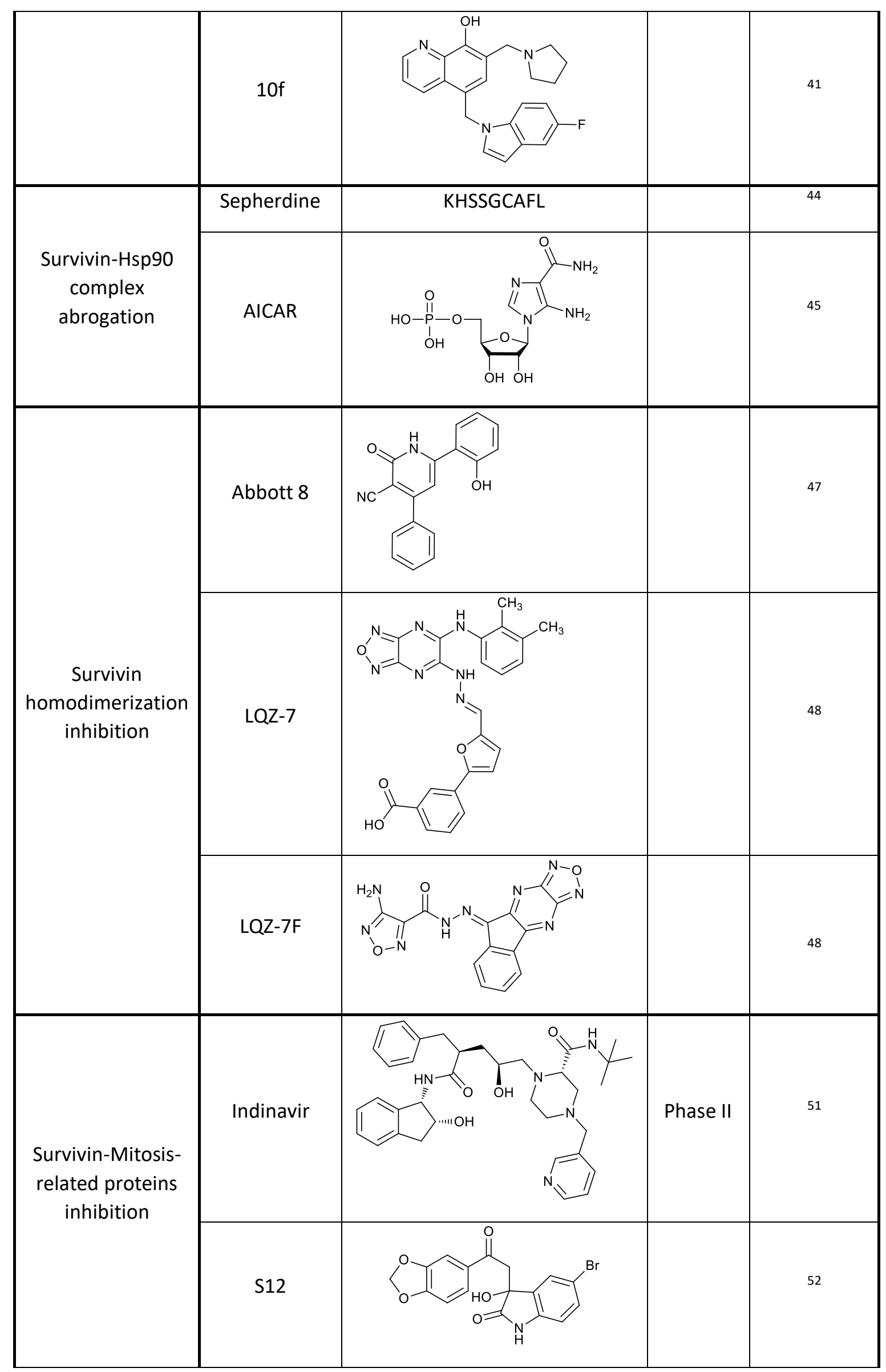




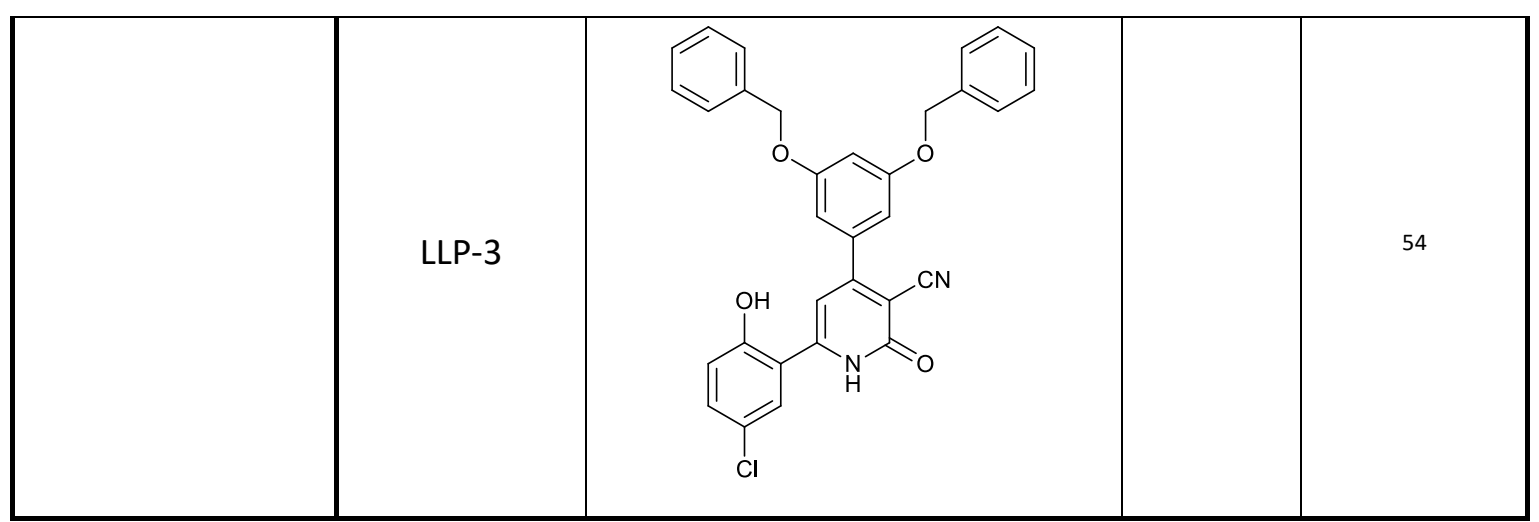

Table 2. Indirect survivin inhibitors.

\begin{tabular}{|c|c|c|c|c|c|}
\hline $\begin{array}{c}\text { Biological } \\
\text { Process }\end{array}$ & Pathway & № & Name & Target & References \\
\hline \multirow{18}{*}{$\begin{array}{l}\text { Cell growth, } \\
\text { proliferation } \\
\text { and survival }\end{array}$} & \multirow{16}{*}{ PI3K/AKT } & 1 & Herceptin & HER-2 & 63 \\
\hline & & 2 & Lapatinib & HER-2 & 64 \\
\hline & & 3 & AG1478 & EGFR & 65 \\
\hline & & 4 & Gefitinib & EGFR & 66 \\
\hline & & 5 & PD153035 & EGFR & 67 \\
\hline & & 6 & LY294002 & PI3K & $\begin{array}{c}57,60,64,65,67- \\
72,75\end{array}$ \\
\hline & & 7 & Wortmannin & $\mathrm{PI} 3 \mathrm{~K}$ & 68,72 \\
\hline & & 8 & MKK-2206 & AKT & 73 \\
\hline & & 9 & SH5 & AKT & 68 \\
\hline & & 10 & AKT inhibitor $X$ & AKT & 69 \\
\hline & & 11 & Rapamycin & mTOR & $57,58,74$ \\
\hline & & 12 & SN50 & NFkB & 75 \\
\hline & & 13 & BAY 11-7082 & NFKB & 61 \\
\hline & & 14 & Panepoxydone & NFkB & 76 \\
\hline & & 15 & Celecoxib & COX-2 & 77 \\
\hline & & 16 & Etodolac & COX-2 & 77 \\
\hline & \multirow{2}{*}{ JAK/STAT } & 17 & TG101209 & JAK2 & 81 \\
\hline & & 18 & AG490 & JAK2 & 82 \\
\hline
\end{tabular}




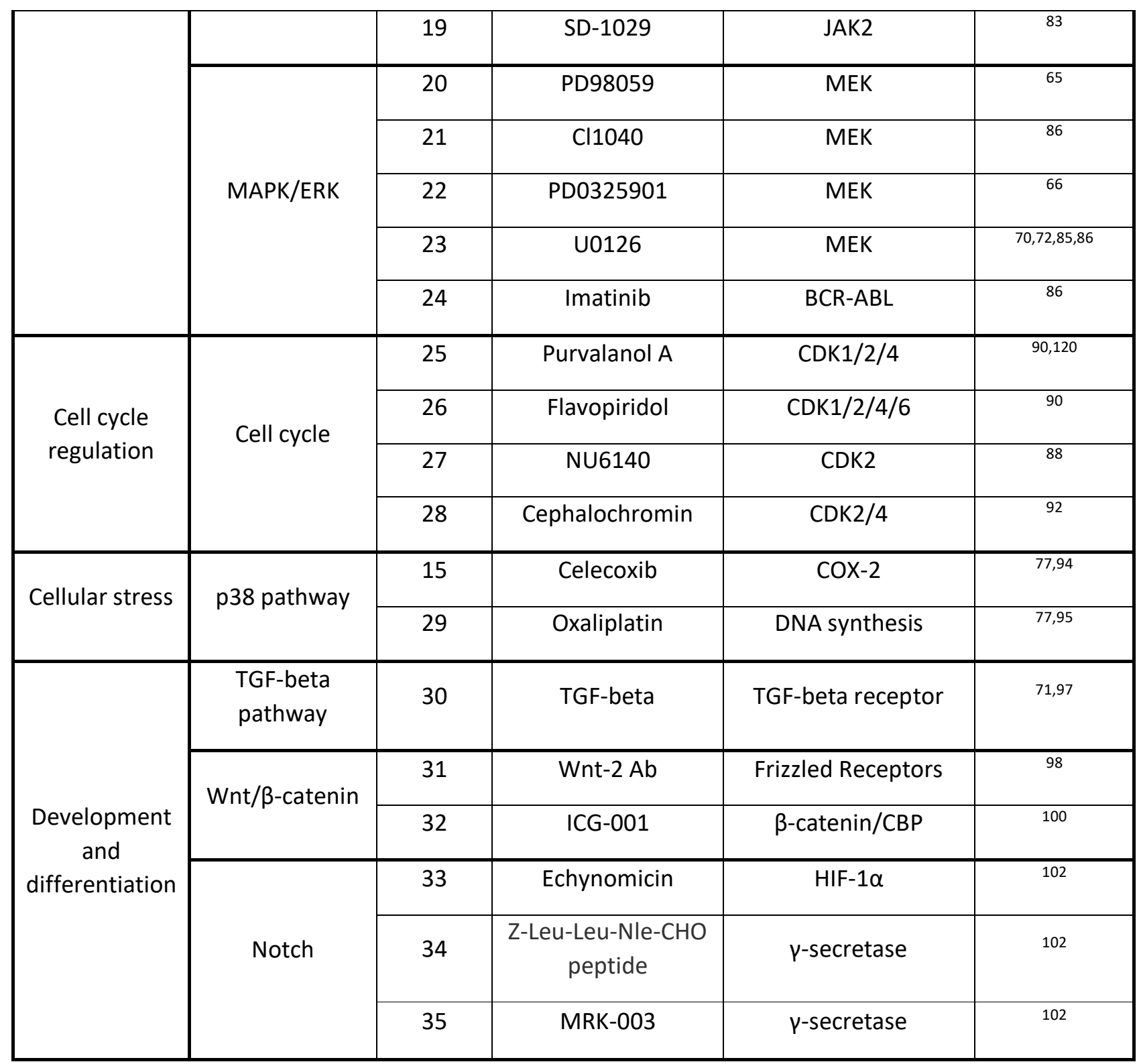

Correlative numbers correspond to those depicted in figure 3 .

\section{Figure Legends}

Figure 1. a. Primary structure of IAP proteins in mammals. The main domains are shown in different colors. b. Structure of survivin protein. c. Structure of dimeric survivin protein.

Figure 2. Survivin sub-cellular functions and direct survivin inhibitors. The main mechanisms of action of direct survivin inhibitors are shown. 1- Transcriptional inhibitors decrease survivin expression levels; 2-Smac mimetics impede that survivin inhibit caspases; 3-Hsp90 inhibitors destabilize the Hsp90-survivin complex, inducing survivin degradation. 4- Homodimerization inhibitors disassemble survivin homodimer, increasing survivin degradation. 5- Mitotic inhibitors prevent CPC complex formation and survivin interaction with other mitosis-related proteins.

Figure 3. Signaling pathways that regulate survivin expression and their corresponding indirect survivin inhibitors. Red numbers correspond to those inhibitors listed in table 2. 
Figure 1.

A

NAIP $\square$ BIR 1 $=$ BIR 2 $\square$ BIR 3 NACHT

C-IAP1 $\square$ BIR 1 BIR 2 $=$ BIR $3=$ UBA CARD RING

C-IAP2 2 BIR 1 BIR 2 BIR 3 UBA CARD RING

XIAP BIR $1=$ BIR 2

Survivin $\sqsubset$ BIR 1 tade

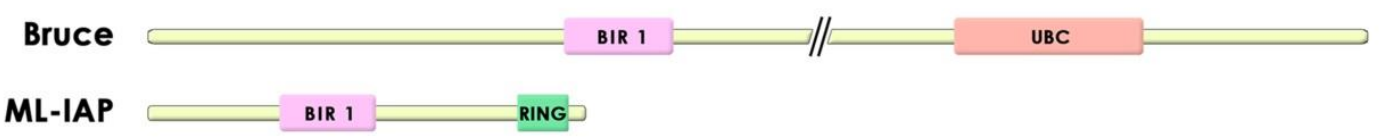

ILP2

B

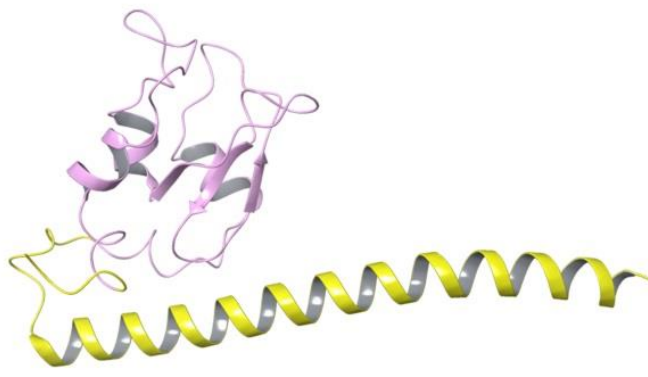

C

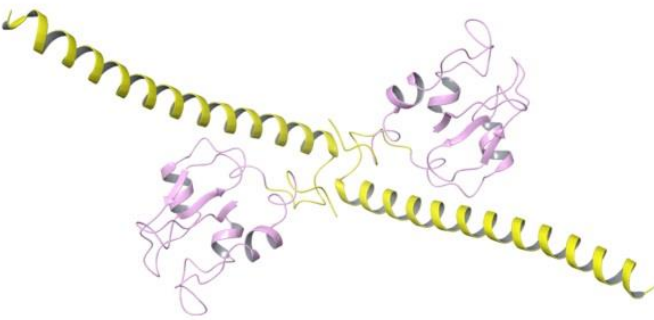


Figure 2.

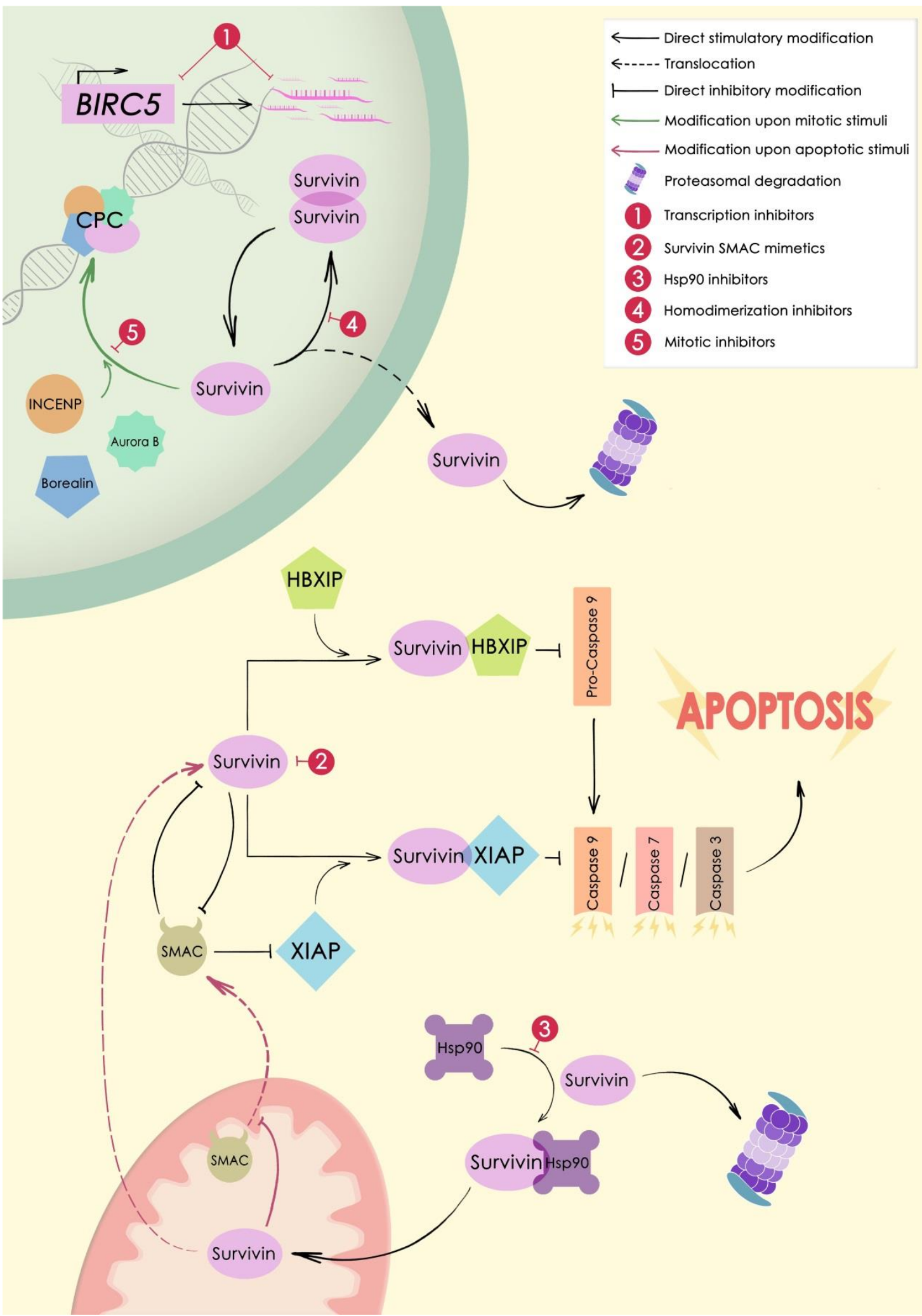




\section{Figure 3.}

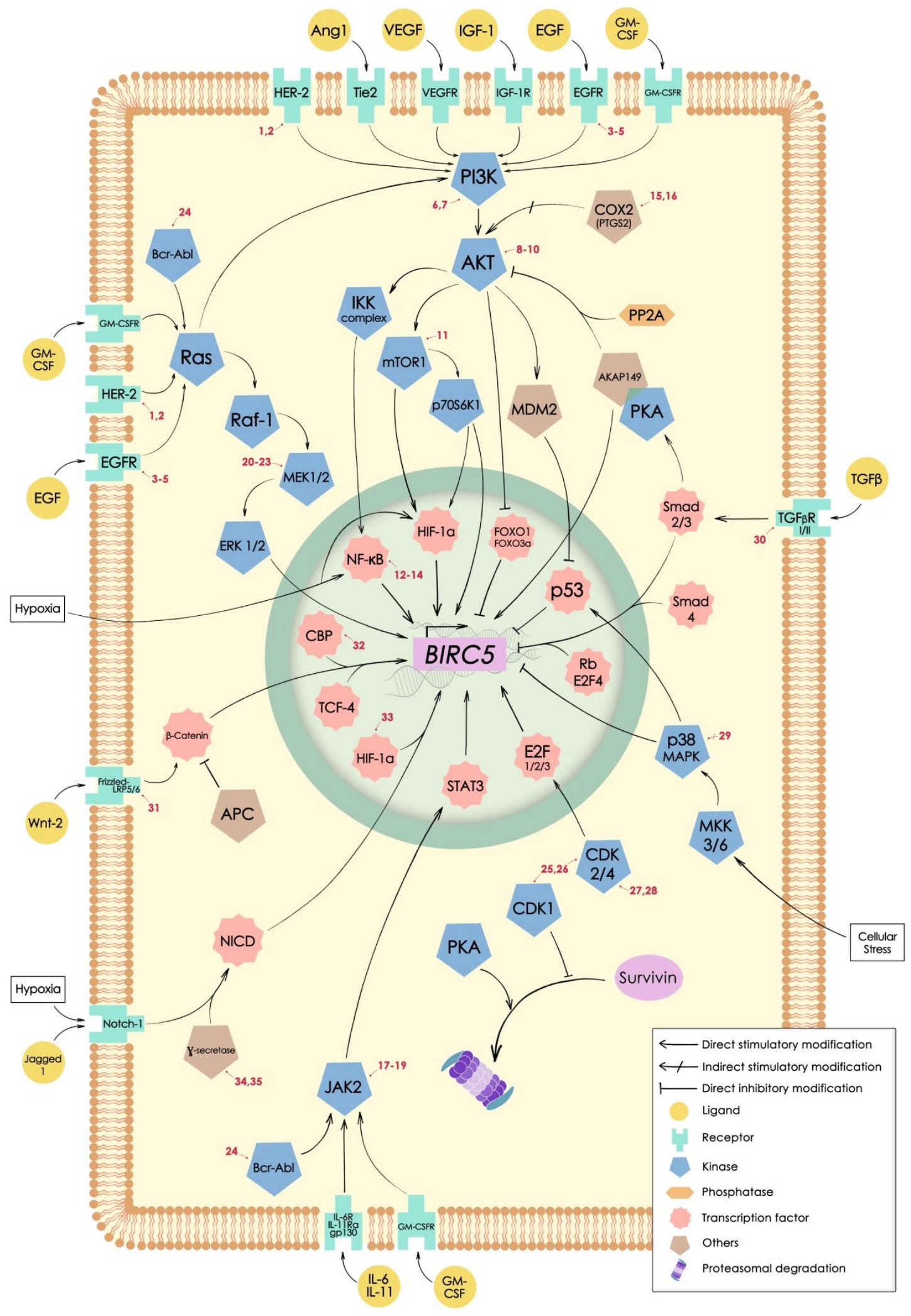

